\title{
INVENTARISASI AMFIBI RESORT CISARUA TAMAN NASIONAL GUNUNG GEDE PANGRANGO BERDASARKAN MUSIM YANG BERBEDA
}

Agus Pambudi Dharma ${ }^{*}$, Meitiyani²

1,2Universitas Muhammadiyah Prof. Dr. Hamka, Jl. Tanah Merdeka Pasar Rebo, Jakarta Timur, 13740, Indonesia

*Corresponding author, e-mail: agus.pambudi@uhamka.ac.id

\section{ABSTRACT}

This study aims to inventory amphibians in the Cimisblung Resort Cisarua Gede Pangrango National Park (TNGGP) the rainy season and dry season. Amphibian data collection was carried out in February - August 2019 in and night (19.00 - 23.00 WIB) days using a visual encounter survey method along 500 meters with the river flow aquatic) and terrestrial among others, below the surface of litter, rock, weathered wood, and in the bush. Amphibians were to view and record their morphology, then matched the images with amphibian identification books. After the next step was identified, the amphibian was photographed for documentation. If amphibians are not identified in the field, the amphibians are taken to the Cibinong Zoology LIPI to be identified. The results obtained were 13 species (Leptobrachium haseltii, Megophrys montana, Duttaphrynus melanostictus, Leptophyryne cruentata, Rhacoporus javanus, Philautus aurifasciatus, dan Nycxtixalus margaritifer, Rana calconata, Huia masonii, Oddorana hosii, Limnonectes kuhlii, Fejevarya limnocharis, Fejevarya limnocharis, and Limnonectes microdiscus) with a difference in the number of species of 5 species between the rainy and dry seasons such as (Leptobrachium haseltii, Duttaphrynus melanostictus, Leptophyryne cruentata, Philautus aurifasciatus, and Nycxtixalus margaritifer).

Keywords: Amfibi, Rainy season, Dry Season, Resort Cisarua, Gede Pangrango National Park

\section{PENDAHULUAN}

Hutan hujan tropis memiliki keanekaragaman hayati (biodiversitas) yang tinggi. Kekayaan alam yang ada di hutan ini didukung oleh kondisi iklim dan tanahnya yang menyebabkan flora dan fauna dapat tumbuh dan berkembang dengan baik. Warisan kekayaan tersebut dapat dijadikan sebagai modal dalam pengembangan dan penerapan ilmu pengetahuan alam dan pemanfaatan lainnya (Balai Besar TNGGP, 2017). Salah satu kekayaan alam yang ada di hutan hujan tropis adalah amfibi terbagi menjadi tiga ordo yakni Gymnophiona (caecilians), Caudata (salamanders), dan Anura (frogs) (Vitt \& Caldwell, 2009).

Gymmophiona (Apoda) atau lebih dikenal dengan sisilia tercatat sekitar 204 jenis. Marga Ichthyophis sekitar 30 jenis marga ini dapat ditemukan di Jawa, Sumatera dan Kalimantan. Salamander dan newt tercatat 676 jenis, anggota jenis salamander tidak terdapat di Indonesia. Anura merupakan katak dan kodok tercatat sekitar 6.525 jenis, lebih dari 500 jenis diantaranya terdapat di Indonesia. Di Indonesia anura mempunyai sebaran yang luas dari Sumatera hingga Papua (Kamsi, dkk 2017; Kamsi, 2008). Penelitian mengenai amfibi sudah banyak dilakukan di berbagai daerah di Indonesia antara lain Kurniati (2007) menyebutkan sebanyak 42 spesies di Sumatera Utara, 25 spesies di Taman Nasional Gunung Halimun (Kurniati, 2005), 20 spesies di Kampus UNNES (Rahayuningsih \& Abdullah, 2012), 36 jenis di Kabupaten Murung 
Raya, Kalimantan Tengah (Rahmania, 2014) dan di kawasan Cimisblung di Resort Cisarua Taman Nasional Gunung Gede Pangrango (TNGGP) (Balai Besar TNGGP, 2017).

Kawasan Cimisblung merupakan suatu kawasan konservasi di Resort Cisarua TNGGP yang terdapat di kaki Gunung Pangrango dan lokasinya masih alami karena masih jarang sekali dilakukan penelitian, eduwisata maupun ekowisata. Hanya satu penelitian yang pernah dilakukan dari Balai Besar TNGGP (2017) di kawasan Cimisblung Resort Cimisblung TNGGP diperoleh 8 spesies amfibi antara lain Huia masonii, Leptobrachium haseltii, Leptophyryne cruentata, Limnonectes kuhlii, Limnonectes microdiscus, Oddorana hosii, Phyrnoidis aspera, dan Rhacoporus javanus.

Pada tahun 2019, perlu dilakukan penelitian lanjutan untuk mendata kembali jenis-jenis amfibi yang ada di lokasi tersebut terutama di musim yang berbeda yakni musim kemarau dan penghujan sehingga hasil penelitian dasar ini diharapkan dapat dijadikan data tambahan dalam mengkonservasi amfibi dan mengembangkan ekowisata di TNGGP.

\section{METODE}

Penelitian dilaksanakan di Kawasan Cimisblung, Resort Cisarua, Taman Nasional Gunung Gede Pangrango (TNGGP). Alat yang digunakan alat tulis, sepatu boot, kamera, dan senter. Pengambilan data amfibi dilakukan selama dua malam sekali, tiap awal bulan dari Februari - Agustus 2019 di musim kemarau dan penghujan. Teknik pengambilan data menggunakan metode survei penjumpaan visual (visual encounter surveys) (Kusrini, 2009). Pengambilan data dilakukan pada pukul 19.00 - 23.00 WIB dengan menyelusuri aliran sungai (aquatik) dan daratan (terrestrial). Amfibi ditangkap dengan tangan untuk mencatat morfologinya seperti bagian tungkai depan dan belakang, garis pariental, dan corak warna yang kemudian diidentifikasi menggunakan buku amfibi seperti karya Ace, dkk., 2015; Iskandar, 1998; dan Kusrini, 2013. Setelah diidentifikasi amfibi difoto untuk dijadikan dokumentasi. Jika amfibi tidak teridentifikasi di lapangan, maka amfibi dibawa ke LIPI Zoologi Cibinong untuk diidentifikasi. Data yang diperoleh dianalisis secara deskriptif.

\section{HASIL DAN PEMBAHASAN}

Hasil pengamatan di kawasan Cimisblung Resort Cisarua Taman Nasional Gunung Gede Pangrango yang berhasil ditemukan pada musim kemarau dan penghujan sebanyak 5 famili dengan 13 spesies amfibi (Tabel 1) antara lain: Megophryidae (Leptobrachium haseltii, Megophrys montana), Bufonidae (Duttaphrynus melanostictus, Leptophyryne cruentata), Rachophoridae (Rhacoporus javanus, Philautus aurifasciatus dan Nycxtixalus margaritifer), Ranidae (Rana calconata, Odorrana hosii, dan Huia masonii), dan famili Dicroglossidae (Limnonectes kuhlii, Fejevarya limnocharis, dan Limnonectes microdiscus).

Hasil penelitian ini lebih besar jumlah jenis amfibinya dibandingkan penelitian Izza \& Kurniawan (2014) di OWA (Objek Wisata Alam) Cangar dan air terjun Watu Ondo ditemukan sebanyak 5 jenis, dan 12 jenis di Resort Sukamade, TN. Meru Betiri (Kurniawan, dkk., 2018), 5 jenis di kawasan Suaka Margasatwa Sermo DIY (Yudha, dkk., 2015), dan di kawasan Cimisblung di Resort Cisarua TNGGP (Balai Besar TNGGP, 2017). Spesies amfibi yang diperoleh di setiap lokasi penelitian mengalami perbedaan hasilnya karena beberapa alasan: 1) perubahan habitat, 2) perbedaan di 
wilayah penelitian tersebut, 3) perbedaan metode dan usaha pencarian sampel, dan 4) perbedaan dalam waktu usaha pencarian (Kusrini, 2007; Rahmania, 2014).

Tabel 1. Jenis Amfibi di Kawasan Cimisblung Resort Cisarua Taman Nasional Gunung Gede Pangrango.

\begin{tabular}{|c|c|c|c|c|}
\hline \multirow{2}{*}{ No } & \multirow{2}{*}{ Nama Family } & \multirow{2}{*}{ Nama Jenis } & \multicolumn{2}{|c|}{ Musim } \\
\hline & & & Kemarau & Hujan \\
\hline \multirow{2}{*}{1} & \multirow{2}{*}{ Megophryidae } & Leptobrachium haseltii & 1 & 0 \\
\hline & & Megophrys montana & 1 & 1 \\
\hline \multirow{3}{*}{2} & \multirow{3}{*}{ Bufonidae } & Duttaphrynus melanostictus & 1 & 0 \\
\hline & & Leptophyryne cruentata & 1 & 0 \\
\hline & & Rhacoporus javanus & 1 & 1 \\
\hline \multirow[t]{3}{*}{3} & \multirow{3}{*}{ Rachophoridae } & Philautus aurifasciatus & 1 & 0 \\
\hline & & Nycxtixalus margaritifer & 1 & 0 \\
\hline & & Rana calconata & 1 & 1 \\
\hline \multirow[t]{3}{*}{4} & \multirow[t]{3}{*}{ Ranidae } & Odorrana hosii & 1 & 1 \\
\hline & & Huia masonii & 1 & 1 \\
\hline & & Limnonectes kuhlii & 1 & 1 \\
\hline \multirow[t]{3}{*}{5} & \multirow[t]{2}{*}{ Dicroglossidae } & Fejevarya limnocharis & 1 & 0 \\
\hline & & Limnonectes microdiscus & 1 & 1 \\
\hline & Jumlah Jenis & & 13 & 7 \\
\hline
\end{tabular}

Keterangan: $0=$ Tidak ada, $1=$ Ada

Tabel 2. Habitat amfibi yang ditemukan di Kawasan Cimisblung Resort Cisarua TNGGP

\begin{tabular}{|c|c|c|c|c|c|c|}
\hline \multirow{2}{*}{ Famili } & \multirow{2}{*}{ Jenis } & \multicolumn{5}{|c|}{ Habitat } \\
\hline & & Air & Tanah & Serasah daun & Batu & Pohon \\
\hline Megophryidae & Leptobrachium haseltii & & $\sqrt{1}$ & & $\sqrt{ }$ & \\
\hline Bufonidae & $\begin{array}{l}\text { Megophrys Montana } \\
\text { Duttaphrynus melanostictus }\end{array}$ & & $\sqrt{ }$ & & & \\
\hline Rachophoridae & $\begin{array}{l}\text { Leptophyryne cruentata } \\
\text { Rhacoporus javanus } \\
\text { Philautus aurifasciatus } \\
\text { Nycxtixalus margaritifer }\end{array}$ & $\sqrt{ }$ & $\sqrt{ }$ & $\sqrt{ }$ & $\sqrt{ }$ & $\begin{array}{l}\sqrt{ } \\
\sqrt{ }\end{array}$ \\
\hline Ranidae & $\begin{array}{l}\text { Rana calconata } \\
\text { Huia masonii } \\
\text { Oddorana hosii } \\
\text { Limnonectes kuhlii }\end{array}$ & $\begin{array}{l}\sqrt{ } \\
\sqrt{ } \\
\sqrt{ }\end{array}$ & $\begin{array}{l}\sqrt{ } \\
\sqrt{ }\end{array}$ & $\begin{array}{l}\sqrt{ } \\
\sqrt{ }\end{array}$ & $\begin{array}{l}\sqrt{ } \\
\sqrt{ } \\
\sqrt{ } \\
\sqrt{ }\end{array}$ & $\begin{array}{l}\sqrt{ } \\
\sqrt{ } \\
\sqrt{ }\end{array}$ \\
\hline Dicroglossidae & $\begin{array}{l}\text { Fejevarya limnocharis } \\
\text { Limnonectes microdiscus }\end{array}$ & $\begin{array}{l}\sqrt{ } \\
\sqrt{ }\end{array}$ & & & $\begin{array}{l}\sqrt{ } \\
\sqrt{ }\end{array}$ & \\
\hline
\end{tabular}

Semua jenis amfibi diperoleh pada musim kemarau sebanyak 13 jenis sedangkan musim hujan diperoleh jenis amfibi berjumlah 7 jenis. Faktor yang menyebabkan musim kemarau lebih banyak spesies amfibi yang ditemukan pada saat penelitian antara lain: 1) aliran sungai, contohnya Leptophyryne cruentata yang ditemukan di aliran sungai yang tidak deras yang sesuai dengan habitatnya, dan 2) adanya lubang pralon air ke masyarakat yang pecah sehingga mengalirkan air di hutan yang menyebabkan tanah menjadi basah dan lembab, contohnya jenis Nycxtixalus margaritifer yang ditemukan di dekat paralon. Faktor ini yang menyebabkan terbentuknya mikrohabitat di daerah tersebut. Putra, dkk (2012) menerangkan mikrohabitat yang sesuai dapat mendukung kehidupan amfibi .

Pada musim hujan di kawasan Cimisblung mempunyai karakteristik sungai dengan aliran airnya deras sehingga tidak ditemukannya jenis Leptophyryne 
cruentata dari famili Bufonidae. Peneliti menduga bahwa Leptophyryne cruentata atau katak merah tidak menyukai aliran sungai yang deras karena bobot tubuhnya kecil sehingga tidak kuat untuk menahan arus sungai. Hal ini sesuai dengan pernyataan Ace, dkk., (2015) dan Iskandar (1998) yang menyebutkan tempat yang disenanginya adalah tepian sungai-sungai kecil atau sungai yang mengalir lambat di daerah pegunungan.

Nycxtixalus margaritifer adalah salah satu spesies yang paling sedikit diperoleh pada saat penelitian sebanyak 1 individu yang hanya ditemukan di serasah. Dalam daftar IUCN, jenis ini berstatus vulnerable (IUCN SSC Amphibian Specialist Group, 2019), selain itu menurut Kusrini (2013) jenis ini sangat jarang dijumpai karena sifatnya yang cenderung bersembunyi di lubang-lubang kayu, hal tersebut dapat menjadi penyebab mengapa spesies ini hanya ditemukan sedikit.

Berdasarkan Tabel 2, jenis Leptobrachium haseltii ditemukan di batu dan tanah, sedangkan famili Megophryidae, jenis Megophrys montana hanya ditemukan di tanah. Famili Bufonidae dari jenis Duttaphrynus melanotictus ditemukan hanya di tanah sedangkan Leptophyryne cruentata (katak merah) ditemukan pada bebatuan disepanjang sungai dan di air.

Amfibi yang ditemukan di semua habitat ada 2 jenis yakni Huia masonii dan Oddorana hosii. Hasil ini berpengaruh pada jumlah individu yang diperoleh. Semakin bervariasi habitat yang menjadi tempat hidup jenis amfibi tertentu, maka semakin banyak peluang jumlah individu yang diperoleh. Spesies Leptophyryne cruentata, Limnonectes kuhlii, Fejevarya limnocharis, dan Limnonectes microdiscus ditemukan di air dan di atas batu. Keempat jenis amfibi ini saat ditemukan pada posisi diam. Posisi ini diduga sedang itirahat dan menunggu mangsa yang melintas didekatnya.

Spesies Nycxtixalus margaritifer (katak mutiara) hanya ditemukan pada serasah daun. Hasil penelitian dari jenis ini habitatnya berbeda dengan yang ditemukan oleh Ace, dkk., (2015) yang menyebutkan katak mutiara hidup di pepohonan (arboreal), spesies ini memiliki jari-jari yang ujung besar dan pipih yang mempunyai jari-jari berselaput renang hampir penuh sampai piringan (Kusrini, 2013).

\section{KESIMPULAN}

Jenis amfibi yang ditemukan di Kawasan Cimisblung Resort Cisarua TN. Gunung Gede Pangrango sebanyak 13 jenis yang tergolong 5 famili.

\section{UCAPAN TERIMA KASIH}

Kami ucapkan terima kasih kepada Ibu Prof. Dr. Suswandari, M.Pd selaku Ketua LEMLITBANG UHAMKA yang sudah mendanai penelitian ini. Bapak Dr. Desvian Bandarsyah, M.Pd selaku Dekan FKIP UHAMKA dan Ibu Drs. Maryanti Setyaningsih, M.Si selaku Ketua Program Studi Pendidikan Biologi FKIP UHAMKA yang sudah mendukung dan memotivasi. Bapak Ir. Herry Subagiadi M. Sc selaku Kepala Balai TN. Gede Pangrango dan beserta Staf yang sudah memberikan izin penelitian dan bantuannya.

\section{REFERENSI}

Ace, Mulyana, A. Syarifuddin, D. (2015). Mengenal Katak di Taman Nasional Gunung Gede Pangrango. Balai Besar Taman Nasional Gunung Gede Pangrango.

Balai Besar Taman Nasional Gunung Gede Pangrango. (2017). Inventarisasi Keanekaragaman Herpetofauna Di Bidang PTN Wilayah III Bogor, Laporan Pelaksanaan Kegiatan Bidang Pengelolaan Taman Nasional Wilayah III Bogor. 
Iskandar. (1998). Amfibi Jawa dan Bali - Seri Panduan Lapangan. Bogor: Puslitbang LIPI.

IUCN SSC Amphibian Specialist Group. (2019). Leptophryne cruentata. The IUCN Red List of Threatened Species 2019: e.T138045255A3020276. http://dx.doi.org/ 10.2305/IUCN. UK.2019-1.RLTS.T138045255A3020276.en. Downloaded on 15 September 2019.

Izza, Q, \& Kurniawan, N. (2014). Eksplorasi Jenis-Jenis Amfibi di Kawasan OWA Cangar dan Air Terjun Watu Ondo, Gunung Welirang, TAHURA R.Soerjo. Jurnal Biotropika, 2(2): 103-108.

Kurniati, H. (2005). Species Richness And Habitat Preferences Of Herpetofauna In Gunung Halimun National Park, West Java. Berita Biologi, 7(5):263-271

Kurniati, H. (2007). The herpetofauna of the gold mining project area in North Sumatra: Species richness before exploitation activities. Zoo Indonesia, 16 (1): 1-11.

Kurniawan, N. Ananda, AA. Kamilah, F. Ardiantoro, A. Bagaskara, SW. Kurnianto, AS. (2018). Exploration of Herpetofauna Habitat as Tourism Attraction: Ecology, Preferences, and Potentials. Journal of Indonesian Tourism and Development Studies, 6(1): 1 - 8.

Kusrini, MD. (2007). Konservasi Amfibi Di Indonesia: Masalah Global Dan Tantangan. Media Konservasi Vol. Xii, No. 2 Agustus 2007 : 89 - 95. Disampaikan Pada Seminar Nasional Herpet Dan Mamalia Air Di Bogor Tanggal 23 November 2006.

Kusrini, MD. (2009). Pedoman Penelitian dan Survei Amfibi di Alam. Bogor: Fakultas Kehutanan IPB.

Kusrini, MD (2013). Panduan Bergambar Identifikasi Amfibi Jawa Barat. Pustaka Media Informasi.

Kamsi, M. (2008). Panduan Lapangan Amfibi \& Reptil di Areal Mawas Propinsi Kalimantan Tengah (Catatan di Hutan Lindung Beratus). Yayasan Penyelamatan Orangutan Borneo The Borneo Orangutan Survival Foundation.

Kamsi, M., Siska H., Akhmad JS., \& Gabriella F. (2017). Buku Panduan Lapangan Amfibi Reptil Kawasan Batang Toru. Medan: Herpetologer Mania Publishing.

Putra, K. Rizaldi. Tjong, D. H. (2012). Komunitas Anura (Amphibia) pada Tiga Tipe Habitat Perairan di Kawasan Hutan Harapan Jambi. Jurnal Biologi Universitas Andalas (J. Bio. UA.) 1(2): 156-165

Rahayuningsih, M., \& Abdullah, M. (2012). Persebaran Dan Keanekaragaman Herpetofauna Dalam Mendukung Konservasi Keanekaragaman Hayati Di Kampus Sekaran Universitas Negeri Semarang. Indonesian Journal of Conservation, 1(1): 110

Rahmania. (2014). Keanekaragaman Amfibi di Kabupaten Murung Raya, Kalimantan Tengah [skripsi]. Fakultas Kehutanan Institut Pertanian Bogor. Bogor

Vitt, L. J. \& Caldwell J. P. (2009). Third Edition Herpetology An Introduction Biology of Amphibians and Reptiles. Academic Press.

Yudha, D. S. Eprilurahman, R. Muhtianda, I. A. Ekarini, D. F., \& Ningsih, O. C. (2015). Keanekaragaman Spesies Amfibi dan Reptil Di Kawasan Suaka Margasatwa Sermo Daerah Istimewa Yogyakarta. Jurnal MIPA, 38(1): 7-12. 